having reference chiefly to the contents of sewers and to carcasses and offal of domestic animals. I am aware of no legislation thus far, which seems to take into account the pollution of rivers by travelers, nor the dangerous and indecent practice of allowing fecal matter to drop from railway coaches.

Art. 370 of the Penal Code of California reads:

"Anything which is injurious to health, or is indecent or offensive to the senses, so as to interfere, with the comfortable enjoyment of life or property by an entire community or neighborhood, or by any considerable number of persons . . . is a public nuisance."

Art. 372 reads :

"Every person who maintains or commits any public nuisance, the punishment for which is not otherwise prescribed, or who willfully omits to perform any legal duty relating to the removal of a public nuisance, is guilty of a misdemeanor."

There is no reason to suppose that the authors of the above enactments had in view the prohibition of the special nuisances herein considered, and it is rather doubtful whether courts would now construe them as applicable to the same, for want of precedent; but it would be practicable to amend these articles so as to make them apply to this offense, or to frame new statutes which would cover the ground.

Obviously, travelers themselves should not be held responsible for committing a nuisance, so long as transportation companies provide no facilities for obviating the same; and legislation should be aimed directly at these companies, holding them responsible and requiring them to provide an adequate remedy.

It is well understood that the law must not ordain what is impracticable, and equally plain that no serious difficulty and expense would be involved in abating such nuisances. No mechanical difficulty exists for a steamboat or railway coach to have its closet provided with a closed receptacle, having suitable means for deodorizing, disinfecting and ventilating, and for discharging the contents into some proper place at short intervals. The details of a contrivance suited to such a purpose need not here be entered into; they belong to the inventor and mechanic rather than to the sanitarian as such.

Aside from considerations of health, it seems strange that respect for common decency has not abolished a practice in travel by land which would have brought a blush to common carriers in the good old days of slow coaches. While inventors and builders of palace cars are doing so much for the comfort and convenience of passengers in other respects, they adhere to a form of closet from which travelers must be excluded at the time when it would be most acceptable (halting at large stations) and which scatters filth and disease along the route. It is to be noted that cholera still lingers in Europe, and meanwhile we must not consider ourselves safe here within two weeks' travel by steam; while the other filth diseases, like the poor, are always with us.

In my judgment the time has come for sanitarians to speak plainly and forcibly on the subject, and to demand of legislators a specific remedy which courts will be bound to apply to this class of offenses against health.

Blank Applications for membership in the Associatio. at the Jovrnal office.

\section{VACCINATION AND RE-VACCINATION.}

Read in the Section on State Medicine at the Forty-fifth Annual Meeting of the American Medical Association, held at San Fraucisco, June $5-8,1894$.

BY EZRA M. HUNT, M.D., LL.D.

SECRETARY OF STATE BOARD OF HEALTH OF NEW JERSEY.

Vaccination for the prevention of smallpox was the first indication that an animal disease could supervene a human disease; that one disease could modify or prevent another, and that a great plague could possibly be abolished from the earth.

It is not our plan just now to outline, even in brief, the marvelous historical record, or the clinical facts as to it for the last hundred years, but only to specify and briefly note changes of view that have modified what we may call the Jenner impression as to it.

1. We have probably come to know that more than one animal disease has the power by inoculation of modifying small pox. Jenner thought that it was the disease known as "grease" in horses, modified by passage through the cow, and again in man so as to prevent smallpox. Now it is probable that there are two or three forms of disease that may supplant variola in man, such as horsepox, sheeppox and cowpox of which some claim that there is more than one effective variety. Dr. Flemming (see paper referred to, Lancet, Aug. 2, 1890,) favors the conclusion that these three variolous diseases in the horse, cow and man are distinct, yet the inoculation of the virus of either of these affections protects from smallpox in man.

2. It is more than probable that kinepox is the smallpox of man which passing through animals is attenuated so as to give a virus which supplants the "caught" smallpox of man and so prevents it. This, in the view of Badcock and Ceely, is the real source of all the varieties of vaccine lymph in use for the prevention of amallpox. It is still, however, disputed by Flemming and various other authorities, the latter calling it a dangerous and fallacious doctrine. It has too many facts as to it, to be so regarded.

Besides various foreign papers, some confirmatory facts in the United States are presented in a paper in the Philadelphia Medical News, March 31, 1883, entitled "Notes on Variola and Vaccina." We think this view has been strengthened the last few years. Dr. McVail in his recent classical essay says: "The whole tendency of the evidence is to show this." (See Treatise on Hygiene and Public Health, Stevenson and Murphy, Vol. ii).

3. Though the identity of the disease is unchanged it has not a uniform type of severity. So far as we can trace in the period before inoculation, and far more before vaccination, the type was uniformly severe and the death rate uniformly high. This is not, as many affirm, so much the case now, independent of vaccination. Leicester and the anti-vaccinationists of England have been in the habit of giving many facts bearing on this point and some are added by Dr. B. A. Whitelegge in his Milroy lectures, London, 1893, "On Changes in Type in Epidemic Diseases," (See Lecture 2 especially. February, 1893). We quote as follows: "Vaccination has profoundly affected the epidemic course of small pox, but changes of type are evident. In the latter part of the last century smallpox contributed on an average about one-tenth of the whole death rate of London, and in 
1796 no less than 18.3 per cent. After this and coin- (smallpox) but which had been attended for that cidently with the introduction of vaccination, its disease by myself only a few months ago. So late ravages lessened until 1830. From 1830 to 1838 the and so good an authority as Hebra regards them as records are missing, but in 1838 the mortality was very closely allied. In the epidemic referred to, some again comparatively high, though below even the of the lighter cases were thus mistaken for varicella. average which prevailed half a century before. After In one case vesicles could only be found in the hair 1838 we can measure its course by actual death rates, of the head.

and a considerable degree of order and even rhythm becomes apparent. Every few years-usually four or five, but sometimes two or three only-it recurred as an epidemic, but with somewhat reduced destructiveness each time until 1855 , which happened to be halfway between 1838 and 1871. .After 1855 minor epidemics continued to recur at about the same interval, but the loss of life on each occasion increased rather than otherwise. Then came the great epidemic or pandemic of 1871 , killing a larger proportion of the population than in 1838. The course of events for twenty years after 1871 was not unlike that which followed the 1838 epidemic-successive outbreaks at intervals of four or five years, decreas. ing in mortality and subsiding after 1885 to a much lowel level than was ever before reached."

4. Protection depends upon the quality and quantity of lymph and is often not permanent, so as to need repetition. It is now fully conceded that there is significance in the character and number of the marks, such as quite justifies a plan of vaccination in use on the continent which repeats the process from week to week until no effect is produced. The English habit is to have four insertions within an area equal to a half inch square and to insist that at least three must be effective in order to have the cicatrix or marks satisfactory. Re-vaccination is now insisted upon as always necessary after a few years.

5 . Through modification of type and through vaccination and re-vaccination we are far more apt than formerly to have mild and walking cases of the disease, so that by reason of this, far greater numbers are exposed to the contagion: In other words, unless vaccination and re-vaccination in all their details are followed up and become the universal habit of the people, smallpox or varioloid will be more largely diffused and more frequent. So that a real remedy becomes the means of extending the disease.

As to this point we note some cases which have quite recently come under our observation:

Within the past year there occurred at Red Bank, in this State, an outbreak of smallpox which seemed singularly persistent. We can generally leave sporadic cases, especially in cities, to local health boards and local physicians. In this case the endemic seemed persistent notwithstanding the ordinary precautions. It even happened that there was doubt between smallpox and chickenpox in early stages, by those of tact and experience.

How this can be is something of a mystery to the physician who has only seen typical cases of each disease and regards the distinction between a vesicle and a pustule as definite." A recent case presented in letters to the London Lancet, Der. 9 and Dec. 23, 1893, by Dr.J. B. H. Smyth, of London, is illustrative. The writer could not conceive how any such doubt could exist until he met with a sporadic case of varicella, (chickenpox) studding every part of the body, and confluent at parts, and attended two patients in one family with varicella which an able neighboring practitioner had pronounced variola

Inquiry showed that many cases were so mild in this epidemic at Red Bank, that persons who had the disease were not confined to the house and so exposed others to the disease. The president of the health board there writes us: "One of our greatest difficulties has lain in the fact that a number of cases have been, so mild that neither the persons themselves nor their physicians have known they were suffering with the disease. Only after other cases have occurred and they were traced to these people, have we been able to discover by their description of their symptoms, that they have had a mild form of varioloid. These cases while not sufficiently severe to confine the patients to the bed, or even to the house, have still been sufficient to cause the spread of the disease and it has been in this way, we think, that the disease sprang up so unexpectedly in different parts of the town. Other similar cases were reported and as re-vaccinations were made when numbers had been exposed, it was evident that in some cases the influence of the contagion was enough to cause some symptoms. It became apparent that important as re-vaccination is, it was incidentally becoming an occasion for the spread of the disease so that stricter inquiry and isolation were necessary."

A few weeks after, similar facts were found at Carteret, a small village in Middlesex County, in this State. Here one of the men traveled to Bayonne, Hudson County, with but little feeling of ill health. One woman examined had no evidence of the disease except two small pustules in the hair. All the cases were mild.

It is a strange record that we have also from the city of Reading, Berks County, Pennsylvania. A late bulletin, January, 1894, announced 710 cases with only 18 deaths and 29 cases remaining under treatment, and several fresh cases up to February, 1894.

Another point for us to note is, that some recent movements in England and some contributions to the literature of smallpox are such as make it essential that the study of the disease, and of vaccination as related thereto, be pursued with new zeal and with minute attention to all details and all facts bearing pon it.

Opposition in England to the law of compulsory vaccination is too formidable to be ignored. It has arrayed against it a strong constituency and has given rise to a most important parliamentary commission, already spending two years in its inquiries. It has shown, as in the case of Leicester, that quick isolation, disinfection, quarantine of exposed healthy persons and thorough sanitary police are very effective in dealing with the disease, although, especially in view of the more recent epidemic in that city, it is plain that the need of vaccination, as an additional protection there, has been greatly underrated. Although it is hard to have patience with some of the wild utterances of the anti-vaccinationists, we do well to review their facts and statements in a judicial spirit.

For a time they had no strong medical support, 
but the various writings of so noted a pathologist and authority as Prof. C. Creighton, of Cambridge, (see his treatise on "Cowpox and Vaccinal Syphilis" and on "Jenner and Vaccination," and especially his article on "Vaccination" in the new Encyclopoedia Britannica,) has contributed much to the apparent argument against vaccination. Still more serious became the scientific position when the learned bacteriologist, Prof. Edgar M. Crookshank, M.B., of University College, London, published 1889-90, two volumes on "The History and Pathology of Vaccination." His work is a sample of great research, is executed with accuracy and is learned and ingenious in its facts and arguments. He concludes that "the inoculation of cowpox does not exercise any specific protective power against human smallpox," and that it is destined to be replaced by the "more rational and comprehensible procedures of the compulsory notification of smallpox and the isolation of all cases of this disease."

"This in the face of the almost concurrent testimony of all nations and the testimony of the great mass of the medical profession, that it is the one great prophylactic that has interrupted what was once the most serious of human contagions, has immensely limited its frequency and fatality and has shown its capacity, when fully applied, for well nigh driving this great pest from the earth."

Dr. Creighton, too, in his more recent work, a "History of Epidemics in Great Britain," shows no change of view. We have in these high authorities and in the minority of persons agreeing with them, a remarkable disregard of clinical experience and no explanation of the accumulated facts as to the mitigation and prevention of this disease.

We regard "such statements as entirely opposed to universal experience; to experiences both of prevention of smallpox and of mitigation of its attacks; to experiences which belong to every quarter of the globe and which are far more to be trusted than the theories of comparative pathology, however suggestive and however interesting these may be."

Yet it will not do, amid such contentions and such opposition, to rest upon the facts of the past and the loyal declaration of our faith.

$a$. We must sift and weigh in full our evidences as the years go on, increase the number and accuracy of classified experiences. We must seek to adjust and harmonize the testimony of the clinician and the biologic pathologist. We must reëxamine sources of lymph supply, account for variations in effect, explain the greater apparent need of re-vaccination and so eliminate errors and fortify the truth in the spirit of scientific investigators and skilled practitioners. In the meantime we must rest boldly and strongly upon the present accepted practice and see to it that the people at large from childhood to age have protection from this marauding pestilence. As an instance of one of these cautions, at a recent meeting of the Society of Medical Officers of Health in London, Feb. 19, 1894, the President, Dr. W. T. G. Woodforde, insisted that "certificates of successful vaccination should specify the number and area of well marked cicatrices."

b. More systematic methods need to be instituted for the production and furnishing of vaccine lymph. At present the whole matter is left in the charge of single individuals, or firms, and it is often retailed by druggists, like any other commodity. This in the face of the fact that there are many different sources of lymph, that they are not of equal reliability, that there is much variation as to freshness of material and that the question whether a person' shall have smallpox, or whether there shall be an epidemic thereof, often depends upon the potency of the single point used. The case is not at all analogous to that of the sale of an ordinary drug.

Dr. Snow, so long the Health Officer of Providence, Rhode Island, was so impressed with the ultimate results of this kind of merchandize dependence, that he kept and distributed through the country a supply of what is usually spoken of as the Jenner lymph, and favored the old method of arm-to-arm vaccination. This was not because he opposed bovine ly mph, but because he thought this the safer method for permanent reliance.

It has already come to pass that some of our best health officers, notably Dr. C. N. Hewitt of Minnesota, are advocating a return to arm-to-arm vaccination, the bovine lymph being used to start new supplies. It is thus not meant to supersede, or to contend with bovine lymph, but while maintaining the old source to secure also a more reliable and ready supply of virus.

If the present method is carried out we believe that vaccination will be less certain in its effects, that revaccination will be more frequently needed and that walking cases will so multiply as to constitute a grave source of epidemic influence.

If this plan is not adopted, bovine lymph should be produced and distributed under national or legal methods and with strict oversight as to details. Never was so much loose vaccination done as now. We hear of 200,000 vaccinations in New York city without charge and many not returning to see if the result is complete.

On the other hand, in London, return is secured and the vaccination must be authenticated. Adopting this plan and having skilled vaccinators, we have the record last year, that of primary vaccinations at the central London station, 7,529 returned, and 7,448 had been successfully vaccinated. The 81 that failed were all successful on a second vaccination. On this plan vaccination will be found to be no failure. The recent article of Dr. McVail, in the second volume of Stevenson and Murphy's "Treatise on Hygiene," together with the constant results of skilful systems of vaccination furnish a complete answer to the contentions of a few biologists and to the charges of anti-vaccination societies.

Yet we sound not too soon this note of warning, for we believe that if the present loose methods are permitted to continue, vaccination will become less and less a preventive of smallpox and its enormous value be greatly impaired.

c. Local health boards and physicians, on the basis of large series of classified facts by competent ob. servers, need to be more in unison as to the necessity for and frequency of re-vaccination. Layet of Bordeaux, a skilled authority, was successful in about 40 per cent. of his re-vaccinations after nine years, but we have no particulars as to various points, such as number of marks, etc.

The Pennsylvania Health Board hand bill, or poster, proclamation says there should be repetition in seven years. One, who represents the New York City Board, says ten years. The Local Government Board, Great Britain, names the age of 12 . Many authori- 
ties name 14, or in general the age of puberty. This vagueness we believe comes largely from imperfect vaccination at the start.

Dr. McVail says that " the rule, that re-vaccination should be performed at 10 to 12 years of age, is not founded on any theory that primary vaccination has then lost its protective power. The power of infantile vaccination against attack by smallpox remains to perhaps at least one-half of its original extent at 20 years of age, and its power against death exists to very considerable extent all through life, as abundantly shown by the statistics of the great smallpox hospitals." This certainly justifies the early vaccination, but is too indefinite for us to rest upon. A series of collective investigations should be made on these points.

The cities of New York and Philadelphia, with adjacent sections of their respective States and of New Jersey, still have outbreaks of the disease. It is occurring, and likely to occur, more than usual in various sections, by reason of the great increase in the number of nationalities that choose their nests in every city and there abide.

There must be more thorough work and more exact discipline as to this whole matter of vaccination, or else the disease will stalk abroad here and there much oftener than heretofore, the number of cases in proportion to deaths will increase, and now and then a severe epidemic remind us of its previous more fatal history.

We present a few of the questions which seem to us to stand in need of such authoritative answer as comes from series of closely studied facts and not as the mere opinions of a committee.

1. What legal or professional method should be adopted to secure a more reliable supply of bovine lymph?

2. How far is the older method of arm-to-arm vaccination still to be commended for adoption?

3 . What mode of insertion of vaccine lymph is to be advised?

4. What directions should health boards and physicians give as to re-vaccination?

5 . What measures are practicable in order to secure a more general primary and secondary vaccination of the population?

6. What after examination should be made, and what should be the form of vaccination certificate? Should it state number of points at which the insertion of lymph produced a distinct depression or cicatrix?

7. What quarantine or other restrictions should be placed on those who have been exposed to small. pox?

We think a committee should be appointed to furnish us facts and evidence touching each of these items, and then to outline a plan for the better securement of the results sought.

At present we name not as conclusions, but as suggestions, a few tentative answers as indicating lines of direction for inquiry.

a. There should be a National vaccine and distributing establishment for bovine vaccine at Washington.

b. Arm-to-arm vaccination should not be wholly abandoned. In our large cities, at least, physicians should arrange to have at hand certified, humanized lymph of which the sources are local and fully known. c. Vaccination direct from a charged ivory point used for scratching, or from a needle, used but for one case, should be relied on.

d. Re-vaccination should be advised for all who have not been vaccinated within ten years, and ofener where there has been special exposure, or there is any doubt as to marks or time of first vaccination.

c. Children should not be admitted to public schools until vaccinated. Provision should be made to encourage general vaccination of infants and youth.

$f$. A vaccination card or certificate should be given stating time and place of vaccination or of re-vaccination, whether there was subsequent examination and at how many points the lymph had taken.

$g$. While time of quarantine must vary somewhat according to circumstances, persons who have been fully exposed, if not quarantined at once, should be under quarantine or watch from the ninth to the fifteenth day after exposure. Read in the Section on Practice of Mediciue, at the Forty fifth Annual
Meetiug of the American Medical Association, held at San Francisco, June $0-8,189 t$

BY JOHN ELIOT WOODBRIDGE, M.D. YovxGstows, oHIO.

It was my intention to have made in this paper an effort to discuss from the scientist's standpoint the etiology and treatment of typhoid fever, but the positive expressions within the past few weeks of the opinions of many of the greatest thinkers of the age, that typhoid fever can not be aborted, and in fact, that the internal exhibition of drugs can have no curative effect, warns me that I have essayed enough and that this paper had better be devoted to strengthening the evidence that the claims already made are valid, and avoid as much as possible enlarging the territory which I shall have to defend. I feel that I do not owe the Section any apology for this change, because this is a disease that according to eminent authority "destroys annually the lives of 50,000 of our people, leads to the very brink of the grave more than half a million more, which during the next twelve months will inflict upon us more injury, suffering and death than any foreign foe could possibly do," and which, I believe, is rapidly increasing. A disease whose geographical distribution is limited by no boundary lines, whose germs may live indefinitely in the icebergs of the frozen North, and thrive in the torrid heat of the equator, can not be accorded too much attention by this AssoCIATION, especially as the medical literature is in such a chaotic state as to be exceedingly confusing to those who place any trust in it. A literature which is not at all creditable to the medical profession as long as its recommendations for treatment form such a medley of contradictions, from "armed expectancy" to the most heroic exhibition of the most dangerous therapeutic agents, from corrosive sublimate to the coal-tar derivatives, including almost every known poison, and all having most enthusiastic devotees until finally, the materia medica having been taxed to the limit of endurance, a new class of enthusiasts has arisen, and now the bath-tub and sponge and the cold pack have their advocates who can see nothing but dire disaster in the use of any 